\title{
PELAYANAN SOSIAL BAGI ANAK JALANAN DAN ORANG TUA ANAK JALANAN DITINJAU DARI PERSPEKTIF PEKERJAAN SOSIAL
}

\author{
Oleh: \\ Intifadah Ummuhanifah, Moch. Zainuddin, \& Gigin Ginanjar Kamil Basar \\ Email: \\ (intifadah0430@gmail.com; moch.zainuddin57@gmail.com; giginkb@mail.unpad.ac.id)
}

\begin{abstract}
Abstrak
Anak jalanan merupakan istilah yang dipakai untuk anak-anak yang hidup di jalan yang umumnya sudah tidak memiliki hubungan dengan keluarganya. Permasalahan yang dihadapi Indonesia saat ini adalah Program penanganan anak jalanan yang dilakukan pemerintah dinilai belum efektif mengurangi jumlah anak jalanan. Banyak program penanganan anak jalanan yang hanya berfokus pada penanganan anak jalanan saja tidak kepada orang tua anak jalanan. Pekerjaan sosial adalah pelayanan profesional yang didasarkan pada pengetahuan dan keterampilan ilmiah guna membantu individu, kelompok maupun masyarakat agar tercapainya kepuasan pribadi dan sosial serta kebebasan. Pelayanan sosial itu sendiri adalah pelayanan yang digunakan untuk semua (communal services) yang berkepentingan untuk memenuhi kebutuhan-kebutuhan sosial dan mengurangi jenisjenis masalah sosial tertentu, khususnya, kebutuhan-kebutuhan dan masalah-masalah yang memerlukan penerimaan publik secara umum atau tanggung jawab sosial dan yang tergantung pada pengorganisasian hubungan-hubungan sosial untuk pemecahannya. Dalam artikel ini akan membahas mengenai pelayanan sosial kepada anak jalanan dan orang tua anak jalanan ditinjau dari proses pekerjaan sosial, yang dilakukan oleh Lembaga Sosial. Adapun tahap-tahap pelayanan yang diberikan sosial meliputi assessment, planning, intervention, evaluation, termination, dan follow up. Upaya peningkatan pelayanan sangat diperlukan oleh pengurus Lembaga Sosial dan Pekerja Sosial, agar tercipta pelayanan sosial yang lebih baik bagi anak jalanan dan orang tua anak jalanan.

Kata Kunci : Anak Jalanan, Pelayanan, Pekerjaan Sosial
\end{abstract}

\section{Pendahuluan}

Anak jalanan merupakan istilah yang dipakai untuk anak-anak yang hidup di jalan yang umumnya sudah tidak memiliki hubungan dengan keluarganya. UNICEF lalu memakai istilah "Street child are those who have abandoned their homes, school and immediate communities before they are sixteen years of age, and have drifted into a nomadic street life (anak jalanan merupakan anak-anak berumur dibawah 16 tahun yang sudah melepaskan diri dari keluarga, sekolah dan lingkungan masyarakat terdekatnya, larut dalam kehidupan yang berpindah-pindah di jalan raya. Menurut Suyanto (2010), "anak jalanan adalah anak-anak yang tersisih, marjinal, dan teralienasi dari perlakuan kasih sayang karena kebanyakan dalam usia yang relatif dini sudah harus berhadapan dengan lingkungan kota yang keras dan bahkan sangat tidak bersahabat". Anak disini adalah setiap individu yang berusia dibawah 18 tahun (Convention on The Right of The Child) atau dalam UU No. 23 Tahun 2002 tentang perlindungan anak, anak merupakan seseorang yang belum berusia 18 tahun, termasuk anak yang masih dalam kandungan. 
Anak jalanan merupakan masalah yang kompleks yang dihadapi Indonesia saat ini. Tercatat Pada Tahun 2004, menurut Pusat Data dan Informasi Kesejahteraan Sosial Departemen Sosial, jumlah anak jalanan sebesar 98.113 orang yang tersebar di 30 provinsi. Khusus wilayah Bandung kurang lebih berjumlah 5.500 anak jalanan (Data Dinas Sosial Provinsi Jawa Barat, 2006) lalu pada tahun 2012 anak jalanan di Kota Bandung berjumlah 20.825 anak. Dari data tersebut terlihat dari tahun ke tahun jumlah anak jalanan semakin bertambah. Semakin bertambahnya anak jalanan di Indonesia tidak terlepas dari faktor-faktor yang melatarbelakangi timbulnya anak jalanan. Menurut Odi Solahudin, ada faktor-faktor yang menyebabkan munculnya anak jalanan yaitu keluarga miskin, perceraian dan kehilangan orang tua, kekerasan keluarga, keterbatasan ruang dalam rumah, eksploitasi ekonomi, dan keluarga homeless. Pada umumnya yang terjadi di Indonesia faktor utama munculnya anak jalanan adalah kemiskinan.

Salah satu faktor kemiskinan adalah kurangnya penghasilan. Penghasilan orang tua anak jalanan yang sedikit, memaksa anak untuk ikut membantu orang tuanya mencari uang di jalanan. Dalam undang-undang No. 23 Tahun 2002 mengenai perlindungan anak, pasal 2 menyebutkan prinsip-prinsip dasar konvensi hak-hak anak yang meliputi non dikriminasi, kepentingan yang terbaik bagi anak, hak untuk hidup, kelangsungan hidup, dan perkembangan, serta penghargaan terhadap pendapat anak. Dari prinsip-prinsip perlindungan anak, anak jalanan tidak mendapatkan kelangsungan hidup dan perkembangan yang baik dalam tumbuh kembang selayaknya anak-anak. Fungsi orang tua yang hilang dalam kehidupan anak jalanan merupakan akar masalah yang kerap dilupakan dalam upaya penanganan anak jalanan selama ini.

Dalam ilmu kesejahteraan sosial, terdapat istilah pelayanan sosial. Pelayanan sosial dimaksudkan sebagai pelayanan yang difokuskan pada bantuan untuk perorangan dan keluargakeluarga yang mengalami masalah penyesuaian diri dan pelaksanaan fungsi-fungsi sosial, atau keterlantaran yang patut disembuhkan. Alfred J. Kahn membedakan pelayanan sosial dalam dua golongan, yaitu:

1. Pelayanan-pelayanan sosial yang sangat rumit dan komprehensif sehingga sulit ditentukan identitasnya, seperti pendidikan dan bantuan dalam bentuk uang yang dilakukan oleh pemerintah.

2. Pelayanan yang jelas ruang lingkup dan batas-batas kewenangannya walaupun selalu mengalami perubahan, seperti kesejahteraan anak dan kesejahteraan keluarga, tetapi juga dapat merupakan suatu bagian dari lembaga-lembaga lainnya.

Program-program pelayanan sosial ini dilakukan baik oleh pemerintah maupun oleh pihak swasta yaitu organisasi-organisasi pelayanan sosial. Pemerintah juga mempunyai program dalam pengentasan anak jalanan, tetapi yang terjadi di lapangan adalah masih banyak terdapat kekurangankekurangan mulai dari akses kepada pelayanan tersebut ataupun cakupan program hanya difokuskan untuk anak jalanan saja. Sehingga dalam upaya mengisi kekurangan program pemerintah, diperlukan peran pihak swasta atau lembaga sosial juga dalam menangani masalah anak jalanan.

\section{Pelayanan Sosial bagi Anak Jalanan}

Dalam meninjau pelayanan sosial bagi anak jalanan dan orang tua anak jalanan, terlebih dahulu harus diketahui mengenai definisi pelayanan sosial menurut para ahli. Di negara-negara berkembang, pelayanan kesejahteraan sosial dimaksudkan sebagai pelayanan yang difokuskan pada bantuan untuk perorangan dan keluarga-keluarga yang mengalami masalah penyesuaian diri dan pelaksanaan fungsi-fungsi sosial, atau keterlantaran yang patut disembuhkan. (Soetarso, 1997:24). Alfred J. Kahn juga menjelaskan mengenai pelayanan sosial, yaitu:

"pelayanan sosial terdiri dari program-program yang diadakan tanpa mempertimbangkan kriteria pasar untuk menjamin suatu tingkatan dasar dalam penyediaan fasilitas pemenuhan kebutuhan akan kesehatan, pendidikan, dan kesejahteraan, untuk melaksanakan fungsifungsinya, untuk memperlancar kemampuan menjangkau dan menggunakan pelayanan- 
pelayanan serta lembaga-lembaga yang telah ada, dan membantu warga masyarakat yang mengalami kesulitan dan keterlantaran."

Definisi lain dikemukakan oleh Sainsbury (dalam Fahrudin, 2012: 48) menyatakan bahwa dalam arti luas, pelayanan-pelayanan sosial adalah pelayanan yang digunakan untuk semua (communal services) yang berkepentingan untuk memenuhi kebutuhan-kebutuhan sosial dan mengurangi jenis-jenis masalah sosial tertentu, khususnya, kebutuhan-kebutuhan dan masalahmasalah yang memerlukan penerimaan publik secara umum atau tanggung jawab sosial dan yang tergantung pada pengorganisasian hubungan-hubungan sosial untuk pemecahannya.

Perserikatan Bangsa-Bangsa menjelaskan mengenai fungsi-fungsi pelayanan sosial, diantara lain adalah:

1. Perbaikan secara terus-menerus kondisi-kondisi kehidupan orang.

2. Pengembangan sumber-sumber manusiawi.

3. Peningkatan orientasi orang terhadap perubahan sosial dan penyesuaian diri.

4. Pemanfaatan dan penciptaan sumber-sumber kemasyarakatan untuk tujuan-tujuan pembangunan.

5. Penyediaan struktur-struktur kelembagaan bagi berfungsinya pelayanan-pelayanan yang terorganisasi lainnya.

Sedangkan Richard M. Titmuss menyatakan fungsi-fungsi pelayanan sosial ditinjau dari segi pandangan masyarakat, yaitu:

1. Pelayanan atau bentuan dalam bentuk uang atau barang yang dimaksudkan untuk menambah kesejahteraan perorangan, keluarga, atau kelompok, baik untuk jangka pendek maupun jangka panjang (program penitipan anak/bayi secara harian).

2. Pelayanan atau bantuan dalam bentuk uang atau barang yang dimaksudkan untuk melindungi masyarakat (hukuman bersyarat dengan bimbingan).

3. Pelayanan atau bantuan dalam bentuk uang atau barang yang dimaksudkan sebagai suatu investasi di dalam diri orang yang penting artinya guna perwujudan tujuan-tujuan sosial (program ketenagakerjaan).

4. Pelayanan atau bantuan dalam bentuk uang atau barang yang dimaksudkan sebagai kompensasi terjadinya gangguan sosial yang diakibatkan oleh kesalahan pelayanan sedangkan tanggung jawab bagi terjadinya kesalahan ini tidak dapat ditentukan (kompensasi kecelakaan industri, kompensasi bagi korban diskriminasi rasial). (Soetarso, 1997:23)

Dalam penanganan anak jalanan dan orang tua anak jalanan yang dilakukan oleh lembaga sosial. Sebagai contoh, di Bandung terdapat bentuk pelayanan sosial kepada anak dan orang tua anak jalanan yang dilakukan oleh BP2M Salman. Program pelayanan sosial tersebut adalah RIKSA (Rumah Inkubasi Keluarga Sayang Anak). RIKSA adalah program pemberdayaan masyarakat perkotaan, khususnya masalah keluarga dan anak miskin yang termasuk di dalamnya adalah anak jalanan. Pada saat ini, alternatif penanganan anak jalanan mengarah ke pemberian pelayanan sosial kepada anak jalanan yang dilakukan oleh lembaga sosial, contohnya seperti yang dilakukan oleh BP2M Salman. Sebagai sebuah bentuk pelayanan kesejahteraan sosial kepada anak, maka pelayanan ini berhubungan dengan Pekerjaan Sosial. Adapun definisi mengenai pekerjaan sosial menurut Apte (1980) dalam Wibhawa, $\operatorname{dkk}(2010: 45)$ menjelaskan mengenai pekerjaan sosial yaitu :

"Social work is a professional service, based on scientific knowledge and skill in human relation. Which help individuals, groups, or communities obtain social or personal satisfication and interdepedence."

Pekerjaan sosial adalah pelayanan profesional yang didasarkan pada pengetahuan dan keterampilan ilmiah guna membantu individu, kelompok maupun masyarakat agar tercapainya kepuasan pribadi dan sosial serta kebebasan. (Friedlander, Walter A. Dan Apte 1980:4) 
Pekerjaan sosial sangat berperan penting didalam pelayanan kepada anak. Proses pekerjaan sosial menurut para ahli berbeda-beda. Dalam buku "Understanding Generalist Practice" menjelaskan 6 tahap dalam proses pekerjaan sosial pendekatan pemecahan masalah (problem-solving approach), yaitu:

1. Assessment

According to Siporin (1975, p.224), assessment is the "differential, individualized, and accurate identification and evaluation of problems, people, and situations and of their interrelations, to serve as a sound basis for differential helping intervention."

"Menurut Siporin (1975, p.224), assessment adalah diferensial, individual, dan identifikasi yang akurat dan evaluasi masalah, orang, dan situasi dan keterkaitan diantara mereka, sebagai dasar yang kuat untuk melakukan intervensi.

Sedangkan Sheafor et al. (1988, p.222) mendifinisikan assessment sebagai "the process of interpreting or giving meaning and conceptual order to data; it is an attempt to make sense out of the data that have been collected." They continue that assessment "is an activity directed toward understanding the client's problem or situation and developing a plan of action (p.224). In the other word, assessment refers to defining issues and gathering relevant information about a problem so that decisions can be made what to do to solve it.

"proses penafsiran atau memberikan makna dan konseptual data; ini adalah usaha untuk membuat arti dari data yang telah dikumpulkan." Mereka melanjutkan bahwa assessment "adalah kegiatan yang diarahkan untuk memahami masalah atau situasi klien dan mengembangkan rencana tindakan (p.224). Dengan kata lain, assessment mengacu pada penetuan masalah dan mengumpulkan informasi yang relevan tentang masalah sehingga dapat dibuat apa yang harus dilakukan untuk memecahkannya.

2. Planning

Assessment mengatur tingakatan untuk intervensi. Perencanaan menentukan apa yang harus dilakukan. Perencanaan didasarkan pada assessment Anda tentang klien situasi, masalah, kebutuhan, dan kekuatan. Selanjutnya, perencanaan berfungsi untuk memandu bagaimana melanjutkan untuk membantu klien.

3. The Intervention

Meliputi perbuatan yang sebenarnya dari rencana. Klien dan pekerja sosial mengikuti rencana mereka untuk mencapai tujuan mereka. Kemajuan selama intervensi harus terus dipantau dan dinilai. Terkadang masalah baru, situasi, dan kondisi mengharuskan rencana diubah.

4. Evaluation

Merupakan evaluasi dari intervensi. Para pekerja sosial harus bertanggung jawab. Artinya, mereka harus membuktikan bahwa intervensi mereka sudah efektif. Setiap tujuan dievaluasi sejauh mana telah tercapai.

5. Termination

Dalam tahapan ini, hubungan pekerja sosial dan klien akhirnya harus berakhir. Penentuan waktu yang tepat dalam terminasi itu penting. Hellenbrand mengutip setidaknya tiga jenis dasar terminasi (1987, hal 1765.): 
- "First, some terminations are "natural". That is goals have been achieved, and it is time for the clients to take what they have learned and go out on their own."

- "Pertama, beberapa terminasi adalah "alami". Itu adalah tujuan yang pernah dicapai, dan sudah saatnya untuk klien untuk mengambil apa yang mereka telah pelajari dan pergi keluar sendiri."

- "Second, other termination is "forced" as, for example, when a worker leaves the agency. Another example involves the client leaving an institution for some reason or losing eligibility for services."

- "Kedua, terminasi lain "dipaksa", contohnya, ketika pekerja sosial meninggalkan agensi. Contoh lain adalah ketika klien meninggalkan sebuah lembaga untuk beberapa alasan atau kehilangan eligibility untuk menerima layanan."

- "Third, there are "unplanned" terminations. The client just does not come back. The family moves. The client is no longer motivated to return."

- "Ketiga adalah "tidak direncanakan'. Klien hanya tidak datang kembali. Keluarganya pindah. Klien tidak lagi termotivasi untuk kembali."

Terminasi paling efektif mengikuti proses ketidaksepakatan dan stabilisasi. Mereka harus mendorong klien untuk berbagi perasaan tentang terminasi. Selain itu, praktisi harus jelas mengidentifikasi kemajuan apa saja yang telah dibuat.

\section{Follow-Up}

Pekerja dapat bingung oleh isu-isu dan tuntutan lainnya. Informasi follow up mungkin sulit untuk didapatkan. Follow up merupakan langkah penting dalam proses intervensi. Dalam meliputi memeriksa untuk mengetahui apakah klien telah mempertahankan kemajuan dan masih berfungsi dengan baik pada mereka sendiri. Apakah klien perlu ditinjau kembali untuk intervensi lain?

\section{Penutup (Simpulan dan Saran)}

Dari penjelasan diatas, ada beberapa kesimpulan yang didapat. Agar menghasilkan program yang lebih efektif dibutuhkan pelayanan sosial yang baik dengan mengikuti semua tahapan dalam proses pekerjaan sosial.

Sebagai seorang pekerja sosial yang bekerja dalam suatu program pelayanan sosial. Maka saran yang bisa diberikan berupa peningkatan pelayanan dengan memperhatikan sistem lingkungan yang disebut dengan sistem dasar. Dalam perpektif pekerjaan sosial, sistem lingkungan memiliki kontribusi signifikan dalam proses dan praktek pekerjaan sosial, Sistem dasar ini merupakan significant factors yang harus diidentifikasi dan diklasifikasikan oleh pekerja sosial dalam menjalankan peran-peran profesionalnya. Pincus dan Minahan (1973) dalam Suharto (1997:319) sistem dasar ke dalam empat jenis, yaitu :

1. Sistem Pelaksana perubahan (change agent system).

Sistem pelaksana perubahan adalah sekelompok orang yang tugasnya memberi bantuan atas dasar keajlian yang berbeda-beda dan bekerja dengan sistem yang berbeda-beda pula ukurannya. Seorang pekerja sosial dapat disebut sebagai pelaksana perubahan, sementara itu lembaga-lembaga kesejahteraan sosial yang mempekerjakannya disebut sebagai sistem pelaksana perubahan

2. Sistem klien

Sistem klien dapat merupakan individu, kelompok, keluarga, organisasi atau masyarakat yang meminta bantuan atau pelayanan kepada sistem pelaksana perubahan

3. Sistem Sasaran 
Sistem sasaran adalah pihak-pihak yang dapat dijadikan sasaran perubahan, atau dijadikan media yang dapat mempengaruhi proses pencapaian tujuan pertolongan.

4. Sistem Kegiatan

Sistem kegiatan menunjuk pada orang-orang yang bekerja sama dengan pekerja sosial untuk melakukan usaha-usaha perubahan melalui pelaksanaan tugas-tugas atau program kegiatan.(Pincus, 1973:53-68)

Adanya 4 sistem ini, diharapkan dapat digunakan oleh pengurus yayasan beserta pekerja sosial agar tecipta pelayanan kesejahteraan sosial bagi anak yang lebih baik.

\section{Daftar Pustaka}

Fahrudin, Adi. 2012. Pengantar Kesejahteraan Sosial. Bandung: PT Refika Aditama.

Huraerah, Abu. 2012. Kekerasan Terhadap Anak. Bandung: Nuansa Cendekia.

Kirst-Ashman, Karen K \& Grafton H. Hull, Jr. 1993. Understanding Generalist Practice. Chicago: Nelson-Hall Publishers.

Suharto, Edi. 2009. Kemiskinan \& Perlindungan Sosial di Indonesia, Menggagas Model Jaminan Sosial Universal Bidang Kesehatan. Bandung: Alfabeta.

Suyanto, Bagong. 2003. Masalah Sosial Anak. Jakarta: Prenada Media Group.

Soetarso. 1997. Kesejahteraan Sosial, Pelayanan Sosial, Dan Kebijaksanaan Sosial. Bandung: Koperasi Mahasiswa STKS.

Sumber lain:

http://apeksi.or.id/index.php/berita/449-2014-bandung-bebas-anak-jalanan (diakses pada tanggal 15 Oktober, Pukul 10.00).

http://www.tempo.co/read/news/2010/01/15/058219384/Pemerintah-Siapkan-Rp-184-Miliar-untukUrus-Anak-Jalanan (diakses pada tanggal 15 Oktober, Pukul 09.00). 